\title{
Role of CT in the Characterization of Renal Masses
}

\author{
Madhuri Atluri ${ }^{1}$, Vamsi Krishna S.V.N ${ }^{2}$ \\ ${ }^{1}$ Professor, ${ }^{2}$ Associate Professor, Department of Radio-Diagnosis, Nimra Institute of Medical Sciences, Vijayawada, Andhra \\ Pradesh, India
}

Corresponding author: Vamsi Krishna S.V.N, Associate Professor, Department of Radio-Diagnosis, Nimra Institute of Medical Sciences, Vijayawada, Andhra Pradesh, Indai

DOI: http://dx.doi.org/10.21276/ijcmsr.2020.5.1.28

BY-NC-ND

How to cite this article: Madhuri Atluri, Vamsi Krishna S.V.N. Role of CT in the characterization of renal masses. International Journal of Contemporary Medicine Surgery and Radiology. 2020;5(1):A128-A133.

\section{A B S T R A C T}

Introduction: The great majority of renal masses are found incidentally on imaging most of these benign some are malignant and need to be surgically removed. Therefore, the proper characterization of these masses is essential so that appropriate management is instituted. Study aimed to assess the role of CT (Computed Tomography scan) in the characterization of renal masses.

Material and methods: A total of 30 patients, suspected clinically of renal masses, those who underwent CT examination were taken for the purpose of the study.

Results: The mean age of the study sample was 36.5 years with a range of 1-72 years. Maximum number of cases were in 61-70 age group. The majority of patients were males. Palpable abdominal mass, flank pain and hematuria were the most frequent presenting complaints. Renal cell carcinoma was the most common lesion followed by cyst. CT scan comes to an accurate diagnosis of renal mass and staging of a renal neoplasm. sensitivity and specificity of CT scan as a reliable diagnostic modality for diagnosis is $96 \%$ and $80 \%$.

Conclusion: CT is very accurate modality for characterization of renal masses but also a necessary prerequisite to preoperative staging of the disease and hence in deciding appropriate management.

Keywords: Computed Tomography Scan, Renal Masses

\section{INTRODUCTION}

Renal masses are found in all age groups, right from the commonly occurring Wilm's tumor in children, renal cell carcinoma in adults, to the rarer multilocular cystic nephroma, which is found in both the age groups, although with different sex predilections. Imaging plays a key role in evaluating these lesions. While the commonest cystic renal lesion is a cortical cyst which includes simple cyst and complicated cyst, the other cystic renal lesions include polycystic renal disease, multicystic dysplastic kidney, multilocular cystic nephroma, renal cysts in hydatid disease, renal cysts associated with systemic diseases like Tuberous sclerosis complex and von Hippel Lindau disease.

Renal tumours are the eight most common malignancy, account for approximately 3\% of newly diagnosed cancers. The majority of tumors ( $85 \%$ to $90 \%$ ) are renal parenchymal lesions, generally renal cell carcinoma in adults. ${ }^{1}$ Others renal tumors in adults include adenoma, oncocytoma, transitional and squamous cell carcinoma of the renal pelvis, lymphoma and metastases. Rare renal neoplasms which are of epithelial origin include small cell carcinoma and juxtaglomerular cell tumour, while those of mesenchymal origin are leiomyoma, hemangioma, lipoma, angiosarcoma and osteosarcoma.

In children, renal neoplasms constitute about 55\% of pediatric abdominal masses. Approximately $87 \%$ of solid renal masses are wilm's tumours, clear cell sarcomas (6\%), rhabdoid tumours (2\%), mesoblastic nephromas (2\%), lymphomas $(0.5 \%)$ and renal cell carcinomas $(<0.5 \%) .^{2}$ The spectrum of radiological investigations in the evaluation of a renal mass range from the plain abdominal radiography, excretory urography, ultrasonography, radionuclide imaging, angiography to CT and MR. As recently as three decades ago, all renal masses discovered by urography or retrograde studies were subjected to surgical exploration due to inability to distinguish between benign and malignant lesions preoperatively.

CT scanning is now well established as the current most satisfactory modality for diagnosis and staging. Various studies have reported accuracy rates of $72 \%$ to $91 \% .^{3}$ CT can distinguish between the perirenal fascia and fat layers and hence differentiate stage I from II tumours, which is of vital significance when only local resection is planned. CT is also more accurate for diagnosing Stage III tumours (except in the retro hepatic portion of IVC). Direct spread in the abdominal well visualized. CT scanning is also appropriate for detecting blood borne metastases to liver, lung and bone. The lungs, liver, lumbar spine and pelvis may be scanned at the same time as the renal examination. The newest technique of Spiral CT may greatly increase the accuracy for detecting small renal neoplasms and staging them as it does not miss any volume due to respiratory movements. It may be possible to assess and follow malignant potential of these small renal 
tumors based on the enhancement pattern.

In general, a CT scan serves as a single step investigation and provides most significant amount of information with regard to the size and location of the lesion, perinephric spread, venous involvement, degree of adenopathy, adjacent organ infiltration and distant blood borne metastases. Study aimed to assess the role of CT (Computed Tomography scan) in the characterization of renal masses.

\section{MATERIALS AND METHODS}

This cross sectional study comprised a total of 30 patients, suspected clinically of having renal masses, from both inpatient and outpatient departments. The computed tomographic was performed in the department of RadioDiagnosis.

Inclusion Criteria: All patients referred for computed tomography, with clinically suspected renal masses were included in this study.

Each patient underwent a thorough clinical evaluation including a detailed history and physical examination. The duration of complaints were noted in each patient. All the patients underwent routine blood investigations. However, this did not form a part of the study. All the patients were made to undergo CT scan as the radiological examination after taking an informed consent for the same. The clinical and CT findings were assessed and compared with pathologic features.

The study was performed using CT machine - GE Hi Speed CT machine. It has a minimum scan time of 1.4 seconds. Prior to the scan, all the adult patients were fasting for at least a period of 4 hours. $600 \mathrm{ml}$ of diluted oral contrast was given over a period of 45 minutes before the scan in fractional doses at intervals of 10 minutes with another 200 $\mathrm{ml}$ just before taking on the CT scanner. In the pediatric age group, about $250 \mathrm{ml}$ over 45 minutes and $100 \mathrm{ml}$ before the scan was given orally.

$10 \mathrm{~mm}$ thick non contrast scans with interscan interval of $10 \mathrm{~mm}$ were performed for the abdomen. Intravenous bolus administration of $80 \mathrm{ml}$ of $65 \%$ iodinated contrast material in adults and $1.5 \mathrm{ml} / \mathrm{kg}$ of $65 \%$ iodinated contrast material in children was used, followed by post contrast scans of 10 $\mathrm{mm}$ thickness at an interscan interval of $10 \mathrm{~mm} .5 \mathrm{~mm}$ thick sections were obtained, wherever necessary for better characterization of the mass.

\section{RESULTS}

In the present study, 30 patients suspected clinically of having renal masses were studied for a period of one year and were subjected to detailed computed tomography examination. In our study, the youngest patient was 1 year old and the oldest was 72 years old with a mean age of 36.5 years. Majority of the patients, $10(33 \%)$ out of 30 were in the age group of 61-70 years. Male patients, 20(67\%) out of 30 formed the majority (table-1).

Out of 30 patients, 17 (57\%) patients complained of pain in the abdomen, $9(30 \%)$ patients complained of hematuria and $8(27 \%)$ patients complained of mass per abdomen. $20(67 \%)$ out of 30 patients also had non-specific complaints like fever, weight loss, weakness, dysuria, anorexia and burring

\begin{tabular}{|l|c|c|}
\hline Age group & $\begin{array}{c}\text { Number of } \\
\text { patients }\end{array}$ & Percentages \\
\hline $1-10$ & 6 & 20 \\
\hline $11-20$ & 0 & 0 \\
\hline $21-30$ & 2 & 6.7 \\
\hline $31-40$ & 3 & 10 \\
\hline $41-50$ & 3 & 10 \\
\hline $51-60$ & 4 & 13.3 \\
\hline $61-70$ & 10 & 33.3 \\
\hline $71-80$ & 2 & 6.7 \\
\hline Total & 30 & 100 \\
\hline Gender & 20 & 66.7 \\
\hline Male & 10 & 33.3 \\
\hline Female & 17 & 56.7 \\
\hline Complaints & 9 & 30 \\
\hline Pain abdomen & 8 & 26.7 \\
\hline Hematuria & 20 & 66.7 \\
\hline Mass per abdomen & \multicolumn{2}{|c|}{} \\
\hline Nonspecific complaints & \multicolumn{2}{|c|}{ Table-1: Demographic distribution in present study } \\
\hline \multicolumn{2}{|c|}{} \\
\hline
\end{tabular}

\begin{tabular}{|l|c|c|}
\hline Diagnosis & $\begin{array}{c}\text { Number of } \\
\text { Patients }\end{array}$ & $\begin{array}{c}\text { Percentage } \\
\text { (\%) }\end{array}$ \\
\hline Renal cell carcinoma & 9 & 30 \\
\hline Cyst & 6 & 20 \\
\hline Abscess & 5 & 17 \\
\hline Wilm's tumour & 4 & 13 \\
\hline Angiomyolipoma & 1 & 3 \\
\hline Hydronephrosis & 1 & 3 \\
\hline Lipoma & 1 & 3 \\
\hline Transitional cell carcinoma & 1 & 3 \\
\hline Metastases & 1 & 3 \\
\hline Neuroblastoma & 1 & 3 \\
\hline \multicolumn{2}{|c|}{ Table-2: CT Diagnosis of various pathologies in present study }
\end{tabular}

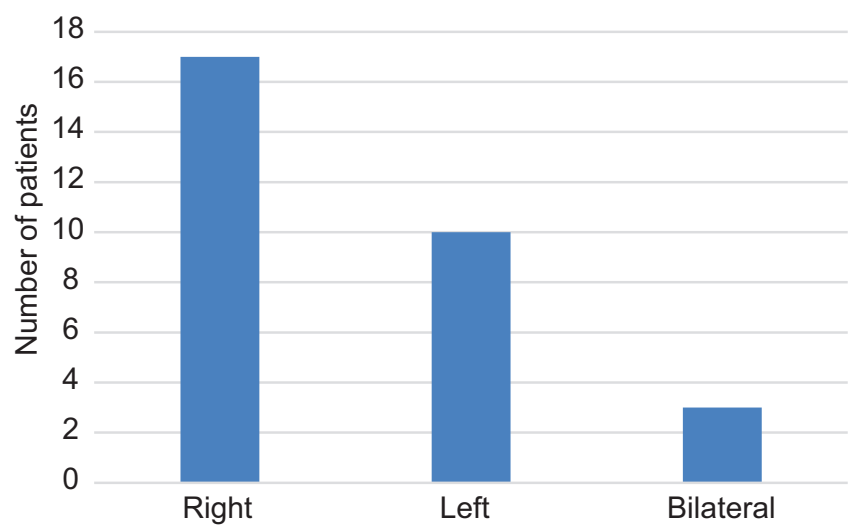

Figure-1: Location of pathological lesion in present study

micturition.

Out of 30 cases, all (100\%) had renal pathology. Of the pathological cases, 9 (30\%) patients had renal cell carcinoma, $6(20 \%)$ had cyst, 5(17\%) had abscess, 4(13\%) had Wilm's tumor and $1(3 \%)$ each had a lipoma, angiomylipoma, transitional cell carcinoma, metastases, hydronephrosis and neuroblastoma invading kidney (table-2). 


\begin{tabular}{|l|c|c|}
\hline Features & $\begin{array}{c}\text { Number of } \\
\text { patients }\end{array}$ & Percentages \\
\hline Renal Cell carcinoma & & \\
\hline Males & 8 & 26.7 \\
\hline Females & 1 & 3.3 \\
\hline Right side & 6 & 20 \\
\hline Left side & 3 & 10 \\
\hline Calcification & 3 & 10 \\
\hline Necrosis & 7 & 23.3 \\
\hline Perinephric spread & 4 & 13.3 \\
\hline Renal vein and IVC involvement & 2 & 6.7 \\
\hline Lymphadenopathy & 1 & 3.3 \\
\hline Metastases & 2 & 6.7 \\
\hline Cystic & 3 & 10 \\
\hline Stage II & 5 & 16.7 \\
\hline Stage III A & 2 & 6.7 \\
\hline Stage IV B & 2 & 6.7 \\
\hline Cyst & & \\
\hline Males & 4 & 13.3 \\
\hline Females & 2 & 6.7 \\
\hline Right side & 1 & 10 \\
\hline Left side & 2 & 6.7 \\
\hline Bilateral & 1 & 3.3 \\
\hline Simple cortical cyst & 1 & 6.7 \\
\hline Parapelvic cyst & 1 & 3.3 \\
\hline Complicated cyst & 2 & 3.3 \\
\hline Polycystic kidneys & 2 & \\
\hline Hydatid cyst & 2 & \\
\hline Table-3: Clinical features of Renal cell carcinoma and cyst in \\
\hline
\end{tabular}

\begin{tabular}{|c|c|c|c|c|}
\hline & & \multicolumn{2}{|c|}{$\begin{array}{c}\text { Pathological } \\
\text { diagnosis of } \\
\text { pathological lesions }\end{array}$} & \multirow[t]{2}{*}{ Total } \\
\hline & & Positive & Negative & \\
\hline \multirow[t]{2}{*}{ CT Diagnosis of RCC } & Positive & 24 & 1 & 25 \\
\hline & Negative & 1 & 4 & 5 \\
\hline \multicolumn{2}{|l|}{ Total } & 25 & 5 & 30 \\
\hline \multicolumn{5}{|c|}{$\begin{array}{l}\text { Table-5: Comparison of CT as a modality for diagnosis of } \\
\text { pathological lesions }\end{array}$} \\
\hline
\end{tabular}
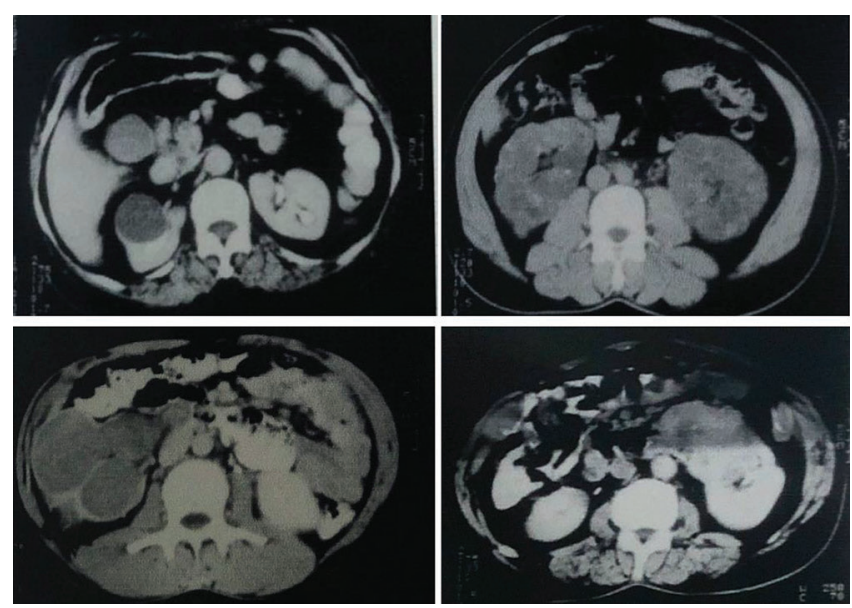

Figure-2: (a) Right renal parapelvic cyst; (b) Bilateral polycystic kidneys; (c) Multilocular cystic renal cell carcinoma of right kidney; (d) Renal cell carcinoma of left kidney with renal vein involvement

Out of the 30 patients, right side involvement was seen in $17(57 \%)$ patients, left side involvement was seen in $10(33 \%)$ patients and bilateral involvement was seen in 3(10\%) cases (figure-1).

\begin{tabular}{|l|c|c|}
\hline Features & $\begin{array}{c}\text { Number of } \\
\text { patients }\end{array}$ & Percentages \\
\hline Abscess & 4 & 13.3 \\
\hline Males & 1 & 3.3 \\
\hline Females & 2 & 6.7 \\
\hline Right side & 2 & 6.7 \\
\hline Left side & 1 & 3.3 \\
\hline Bilateral & 2 & 6.7 \\
\hline Perinephric extension & & \\
\hline Wilm's tumour & 3 & 10 \\
\hline Males & 1 & 3.3 \\
\hline Female & 3 & 10 \\
\hline Right side & 1 & 3.3 \\
\hline Left side & 1 & 3.3 \\
\hline Calcification & 4 & 13.3 \\
\hline Necrosis & 3 & 10 \\
\hline Perinephric spread & 1 & 3.3 \\
\hline IVC involvement & 1 & 3.3 \\
\hline Metastases & 2 & 6.7 \\
\hline Stage II & 1 & 3.3 \\
\hline Stage III & 1 & 3.3 \\
\hline Stage IV & present study & \\
\hline Table-4: Clinical features of Abscess and wilm's tumor in \\
\hline
\end{tabular}

Out of 30 patients, 90 (30\%) patients had renal cell carcinoma. The age ranged from $22-72$ years with a mean age of 47 years. $6(67 \%)$ patients had right side involvement and $3(33 \%)$ patients had left side involvement. 8 (89\%) patients were males and $1(11 \%)$ was a female (table-3).

$3(33 \%)$ out of 9 patients showed calcification, 7 (78\%) had necrosis, perinephric spread was present in 4 (44\%) patients, ipsilateral renal vein was involved in $1(11 \%)$ patient, renal vein and inferior vena cava were involved in $1(11 \%)$ patient, $1(11 \%)$ patient showed para-aortic lymphadenopathy and 2(22\%) patients showed distant metastases. 3(33\%) patients showed cystic component.

Out of the 9 patients, the carcinoma was in stage II in $5(56 \%)$ patients, stage III A in 2(22\%) patients and IV B in $2(22 \%)$ patients. $6(20 \%)$ patients showed cystic masses of kidney. $4(67 \%)$ patients were males and 2(33\%) patients were females. Age of the patients ranged from 40-65 years with a mean age of 52.5 years. 3(50\%) patients had right kidney involvement, 2 (33\%) patient had left kidney involvement and $1(17 \%)$ patient showed involvement of both kidneys.

2(33\%) patients had simple cortical cyst, 1(17\%) had a parapelvic cyst, $1(17 \%)$ had a cyst complicated with hemorrhage, $1(17 \%)$ patient showed bilateral polycystic kidneys and $1(17 \%)$ patient showed a hydatid cyst. 
$5(17 \%)$ patients out of 30 patients had abscess in kidney. Age of these patients ranged from 2-71 years, the mean age being 36.5 years. Out of the 5 Patients, 2(40\%) showed right kidney involvement, left kidney was involved in 2(40\%) patients and $1(20 \%)$ patient showed involvement of both kidneys. In 2(40\%) patients, the abscess was extending into the ipsilateral psoas muscle. $4(80 \%)$ patients were males and $1(20 \%)$ patients was a female.

Out of 30 patients, 4(13\%) showed Wilm's tumour, 3(75\%) patients showed involvement of right kidney and 1(25\%) patient showed left sided involvement. The age of the patients ranged from 1-6 years with a mean age incidence of 3.5 years. $3(75 \%)$ children were males and $1(25 \%)$ child was a female (table-4).

Out of 4 patients, $1(25 \%)$ child had involvement of inferior vena cava with thrombus within it and $1(25 \%)$ child had metastases to brain. The tumour was in stage II in $2(50 \%)$ patients, stage III in $1(25 \%)$ patient and stage IV in $1(25 \%)$ patient.

1(3\%) female patient, aged 65 years showed angiomyolipoma of right kidney. $1(3 \%)$ female patient of 45 years age had a horseshoe kidney with right sided hydroneprhosis due to pelvi-ureteric junction obstruction. 1(3\%) male patient of 67 years age showed lipoma in left kidney. 1(3\%) 63 years old female patient showed transitional cell carcinoma of left kidney. 1(3\%) children, aged 2 years had neuroblastoma invading the superior pole of right kidney. 1(3\%) 63 years old female patient had multiple metastases in both kidneys and liver.

Based on recorded findings, we calculated sensitivity and specificity of CT scan as a reliable diagnostic modality for diagnosis. From this study, we observed Sensitivity of $96 \%$ and Specificity of $80 \%$ (table-5).

\section{DISCUSSION}

The management of renal neoplasms requires characterization and associated determination of extent of disease prior to surgery. The surgical approach varies with the extent of the tumor. Computed Tomography, today forms an excellent modality for answering most of the pertinent questions prior to surgery. It is considered the imaging modality of choice for characterization and staging of disease. Hence, this study was performed with the objective of assessing the role of CT in the characterization and detection of extent of the disease. The overall accuracy of CT in staging was also assessed. In this study, 30 patients of clinically suspected renal masses underwent CT examination. 25(83\%) patients underwent ultrasound examination prior to CT. The age group was of 1 year to 72 years. There were 20 males and 10 females with male to female ratio of 2:1. Renal cell carcinoma comprised a majority of renal masses with a frequency of $30 \%$. Renal cell carcinoma was the most common renal neoplasm and comprised $53 \%$ of all renal neoplasms and $82 \%$ of malignancies in adult age group. Renal cell carcinoma was most common in 71-80 age group (100\%), followed by 61 70 age group (44\%). Thus, the sixth and seventh decades accounted for $66 \%$ of renal cell carcinomas with the peak incidence being in the sixth decade. Through the age below 30 years in uncommon for renal cell carcinoma, there was one case encountered.

With regard to the sex distribution, there was a male preponderance with $89 \%$ being males and 11\% females. Thus, the male to female ratio was 8:1. These epidemiological features corroborate well with those observed by Similar results were seen in studies by Birnbaum et al. ${ }^{4}$, Welch et al. ${ }^{5}$, Sun $\mathrm{M}$ et al. ${ }^{6}$, Seuong Won Choi et al. ${ }^{7}$

Hematuria was present in $44 \%$ of patients, flank pain in $33 \%$ and a palpable abdominal mass in $11 \%$. The classic triad of hematuria, flank pain and palpable mass seen in $11 \%$ of the cases. Constitutional symptoms such as fever, loss of weight, anorexia and weakness were seen in $67 \%$ of the patients. These clinical features are consistent with those stated by Dekernion et al. ${ }^{8}$

About $67 \%$ of renal cell carcinomas were seen in the right kidney while 33\% were present in the left kidney. There was no case involving both kidneys. Majority of the tumours (56\%) were more than $10.0 \mathrm{~cm}$ in size. There was no small renal cell carcinoma $(<3.0 \mathrm{~cm})$ contrary to the findings of Bosniak M A et al. ${ }^{9}$ This could be attributed to the fact that this hospital is a health care center of the tertiary level and there is a significant time lag between the patients first clinical presentation and subsequent work up at this hospital. Thus, reliable incidence of small renal carcinoma could not be determined in our study.

There was not a single tumor which exhibited hyper dense CT values. All the tumors showed heterogeneous, patchy post contrast enhancement. This could be attributed to the necrosis and hemorrhage occurring in tumors with large size. Calcification was seen in $33 \%$ of cases with renal cell carcinoma. In most of the cases it was of the non-peripheral, central type with an amorphous, nodular or stippled pattern. Peripheral calcification was only occasionally seen. These findings corroborate with the findings of Weyman et $\mathrm{al}^{10}$, who observed calcification in $8-18 \%$ of cases of RCC with $90 \%$ of them showing non-peripheral central calcification. However, Zagoria et al have reported an incidence of calcification in $31 \%$ of RCC and is probably the highest reported in any series. ${ }^{11}$

Cystic changes were seen in 3 cases. However, there were no cases of simply cystic renal cell carcinoma. The higher incidence in this study, as compared to $5 \%$ to $7 \%$ reported by Murphy et $\mathrm{al}^{12}$ and $2.3 \%$ to $7 \%$ by Gibson et $\mathrm{al}^{13}$ is probably due to that most tumors were large at presentation and therefore associated with necrotic areas which had attenuation values similar to that of water. Fat attenuation values were not detected in any of the 9 cases of renal cell carcinoma. Thus, through there have been case reports, to the contrary, presence of fat in RCC appears to be a rare finding. Pelvicalyceal distortion was seen in 33\% and is attributed to larger tumour size and perinephric spread which was evident in $44 \%$ of cases. Tumor staging of RCC was done following the Robson's staging system-56\% as Stage II, 22\% as Stage III A and $22 \%$ as Stage IV B, though approximately $25 \%$ to $40 \%$ patients were said to present with metastatic disease. The higher incidence of Stage IV disease in this study is probably due to the lag between patient presentation and work up and also due to average larger tumor size. ${ }^{14}$

Perinephric spread was detected in 4 case (44\%). 22\% of 
patients had evidence of vascular involvement. 2 case had level 1 Involvement, i.e. thrombosis of the renal vein and inferior vena cava. The detection of the level of involvement significantly alters the surgical approach. Para-aortic lymphadenopathy was seen in $11 \%$ of patients. Distant metastases were seen in 22\%, 1 patient had pulmonary metastases and one had liver metastases.

The higher rate of detecting perinephric spread in our study as compared to that by Johnson et $\mathrm{al}^{15}$, is probably due to the fact that perinephric soft tissue stranding was also considered as incidence of invasion, while Johnson et al took only presence of soft tissue mass in the perinephric space as evidence of perinephric invasion.

Venous involvement was identified in $22 \%$ of cases. This is in agreement with the accuracy rates started by M. Boukobza et $\mathrm{al}^{16}$, however less than those observed by Johnson et al Ultrasound diagnosed the lesion as a probable renal cell carcinoma in $77 \%$ of the patients while $23 \%$ did not undergo a prior sonographic examination. All the patients underwent a biopsy which showed clear cell carcinoma histologically.

The next commonest lesion found in our study was cystic lesion occurring in 20\% of the patients. Cysts were most commonly found in 60-70 years age group (67\%). There was a male preponderance with $67 \%$ of the patients being males and $33 \%$ females, thus making the male to female ratio $2: 1$. All the patients presented with at least one complaint pertaining to the classic triad. About $50 \%$ of the cystic lesions were found in right kidney and 30\% in the left while $17 \%$ involved both the kidneys. $50 \%$ of the patients had simple cysts i.e., Class II. The involved kidney size was increased in $33 \%$ of the patients.

$67 \%$ of the patients underwent a prior ultrasound examination. The diagnosis of complex cyst was missed out on ultrasound. $17 \%$ of the patients showed renal absesses. There was a male preponderance again with male to female ratio being $4: 1$. In $40 \%$ of cases, the involvement was on right side and $40 \%$ of patients had left renal involvement was on right side and $40 \%$ of patients had left renal involvement. $20 \%$ showed the involvement of both kidneys. There was no age preponderance. Abscess was seen in patients ranging from 2 years to 71 years. $100 \%$ of the patients presented with pain. Fever was reported in $80 \%$ of the cases. Patients occasionally complained of hematuria.

Gas is found in $80 \%$ of the cases. $60 \%$ of the cases show non enhancing central portion, a finding which corroborates with that of Soulen M C et al. $40 \%$ of the cases show extension of the abscess onto the ipsilateral paoas muscle. The abscess is extending into Gerota's fascia in $20 \%$, a finding proved by Soulen $\mathrm{M} \mathrm{C}$ et al. ${ }^{17}$ The affected kidney size was increased in $40 \%$ of the patients. A prior ultrasound examination proved to be wring in $20 \%$ of the cases. In one case, diagnosed as abscess on CT examination, FNAC showed a clear cell renal carcinoma.

Wilm's tumour accounted for $25 \%$ of renal neoplasms and $100 \%$ of pediatric renal neoplasms. ${ }^{18}$ All the cases were proven by surgical pathology. 2 patients were below the age of 5 years while 2 patients were between 5-10 years. The male to female ratio was $3: 1$. All the patients presented with a palpable flank mass. They also complained of flank pain and fever.

In $75 \%$ the right kidney was involved while in $25 \%$ the left kidney was involved.

All the tumours were large in size $>5 \mathrm{cms}$ in diameter. Necrotic/Cystic arrears were seen in $100 \%$ of cases. Calcification was identification in 25\%. All the tumours showed heterogeneous post contrast enhancement. Staging was done according to that suggested by National Wilm's tumour study staging system. ${ }^{16} 50 \%$ were in stage II, 25\% were in stage II and $25 \%$ in stage IV. Perinephric spared was seen in 3 patients (75\%), venous invasion in 1 patient (25\%) and metastases to brain in 1 patient (25\%).

Transitional cell carcinoma of the renal pelvis accounted for $6 \%$ of renal tumours. ${ }^{17}$ The patient had complaints of hematuria and flank pain. The lesion was hypodense on the unenhanced scan and showed minimal homogenous post contrast enhancement. Since the mass was epicentered on the renal pelvis, maintained the renal contour and showed no evidence of venous invasion, it suggested a diagnosis of a urothelial tumour of the renal pelvis, TCC being the most common. ${ }^{18}$

Angiomyolipoma was seen in 3\% of patients. The patient was a female aged 65 years presenting with flank pain and hematuria. The CT findings were quite typical of angiomyolipomas with clear evidence of fat attenuation areas. Being perinephric spread was seen confirming reports of Reiff et al which state perinephric spread of angiomyolipomas. However venous thrombosis was not seen. ${ }^{19}$

Nonlymphomatous renal metastases were seen in 1 patients (3\%). The primary was not known. The CT finding were only suggestive and had to be confirmed by FNAC which was positive for malignancy. One patient showed a lipoma and another focal hydronephrosis of right kidney due to pelviureteric junction obstruction. One patient showed invasion of right kidney by a large neuroblastoma. There was perinephric spread and inferior vena cava thrombus. The lesion showed calcification and necrosis and showed heterogeneous post contrast enhancement. The affected kidney was enlarging in size.

Other renal tumours like adenoma, oncocytoma, lymphoma juxtaglomerular tumors and pediatric tumors such as clear cell sarcoma, mesoblastic nephroma, multilocular cystic nephroma and rhabdoid tumour of the kidney were not encountered in our study and are uncommon with some of the tumours being rare.

From the present study, we found one case of false positive and one case of false negative detected by CT scan while evaluating renal masses. Based on recorded findings, we calculated sensitivity and specificity of CT scan as a reliable diagnostic modality for diagnosis we observed Sensitivity of $96 \%$ and Specificity of $80 \%$.

\section{CONCLUSION}

Computed tomography, today is one of the most optimal imaging modality for the characterization of renal masses and diagnosis and staging of renal neoplasms. It is definitely superior to other imaging modalities such as excretory urography, angiography and ultrasonography. It is as accurate as MRI in the overall staging, but is inferior to MRI in 
sensitivity of detecting venous invasion.

This study found CT to be of great value in the characterization of the tumour. Features of the neoplasm such as anatomic location and relation to adjacent organ, size, calcification, cystic areas, haemorrhage and fat were all accurately assessed. Though the CT characteristics alone were not always enough to make a specific diagnosis, talking clinical features into account enable an accurate preoperative diagnosis to be made.

CT played an essential role in the staging. CT accurately staged about $77 \%$ of renal cell carcinomas and $75 \%$ of Wilm's tumors. CT also had accuracy rates between $80 \%$ to $90 \%$ for identifying perinephric spread, venous invasion, retroperitoneal lymphadenopathy and adjacent organ invasion.

Thus, this study confirms that CT is not only a very accurate modality for characterization of renal masses but also a necessary prerequisite to preoperative staging of the disease and hence in deciding appropriate management. With the advent of spiral CT scanning, the role of CT in the evaluation of renal neoplasms is very likely to increase and make it comparable to MRI, which is challenging CT as a more accurate method of staging.

\section{REFERENCES}

1. Tan PH, Cheng L, Rioux-Leclercq N, et al. Renal tumors: diagnostic and prognostic biomarkers. Am J Surg Pathol. 2013;37(10):1518-1531.

2. Shehata, Bahig \& Naguib, Mina \& Lin, Jenny \& Khanna, Geetika. (2015). Malignant Renal Tumors. 271-295.Cohan RH, LS S, M K, JC B, IR F. Renal masses: assessment of corti- comedullary-phase and nephrographic-phase CT scans. Radiology. 1995;96:445-51.

3. Kang SK, Huang WC, Pandharipande PV, Chandarana H. Solid renal masses: what the numbers tell us. AJR Am J Roentgenol. 2014;202(6):1196-1206.

4. Birnbaum BA, Jacobs JE, Ramchandani P. Multiphasic renal CT: comparison of renal mass enhancement during the corticomedullary and nephrographic phases. Radiology. 1996;200(3):753-8.

5. Welch TJ, LeRoy AJ. Helical and electron beam CT scanning in the evaluation of renal vein involvement in patients with renal cell carcinoma. J Comput Assist Tomogr. 1997;21(3):467-71.

6. Sun M, Abdollah F, Bianchi M, Trinh Q-D, Jeldres C, Tian Z, et al. A stage-for-stage and grade-forgrade analysis of cancer-speci c mortality rates in renal cell carcinoma according to age: a competing-risks regression analysis. Eur Urol. 2011;60(6):1152-9.

7. Choi S, Jeon SH, Chang S. Urological Oncology Characterization of Small Renal Masses Less than $4 \mathrm{~cm}$ with Quadriphasic Multidetector Helical Computed Tomography: Di erentiation of Benign and Malignant Lesions. Korean J Urol. 2012;53(3):159-64.

8. De Kernion JB, Golub SH, Gupta RK, Silverstein M, Morton DL. Successful transurethral intralesional BCG therapy of a bladder melanoma. Cancer. 1975;36(5):1662-1666.

9. Bosniak MA. e current radiological approach to renal cysts. Radiology. 1986;158(1):1-10.

10. Weyman PJ, McClennan BL, Lee JK, Stanley RJ. $\mathrm{CT}$ of calci ed renal masses. AJR Am J Roentgenol. 1982;138(6):1095-9.

11. Zagoria RJ, Wolfman NT, Karstaedt N, Hinn GC, Dyer RB, Chen YM. CT features of renal cell carcinoma with emphasis on relation to tumor size. Invest Radiol 1990;25(3):261-6.

12. Murphy N, Ward HA, Jenab M et al. Heterogeneity of colorectal cancer risk factors by anatomical subsite in 10 European countries: a multinational cohort study. Clin Gastroenterol Hepato 2018;23(6):34-40.

13. Gibson W.J., Hoivik E.A., Halle M.K., TaylorWeiner A., Cherniack A.D., Berg A., Holst F., Zack T.I., Werner H.M., Staby K.M. The genomic landscape and evolution of endometrial carcinoma progression and abdominopelvic metastasis. Nat. Genet. 2016;48(5):848-855.

14. Caltel WR, Webb JA, Hilson AJ. Clinical Renal Imaging Chichester: John Wiley and Sons. 1989

15. Johnson SR, Cordier JF, Lazor R, Cottin V, Costabel U, Harari S, et al. European Respiratory Society guidelines for the diagnosis and management of lymphangioleiomyomatosis. Eur Respir J. 2010;35(4):14-26.

16. M. Boukobza, I. Crassard, M.G. Bousser and H. Chabriat: MR Imaging Features of Isolated Cortical Vein Thrombosis: Diagnosis and Follow-Up: American Journal of Neuroradiology 2009;30(3):344-348

17. Clark TW, Groffsky JL, Soulen MC. Predictors of long-term patency after femoropopliteal angioplasty: results from the STAR registry. J Vasc Interv Radiol. 2001;12(7):923-33.

18. Bhatnagar S. Management of Wilms' tumor: NWTS vs SIOP. J Indian Assoc Pediatr Surg. 2009;14(1):6-14.

19. Kebebew E, Reiff E, Duh QY, Clark OH, McMillan A. Extent of disease at presentation and outcome for adrenocortical carci- noma: have we made progress? World J Surg 2006;30(6):872-878.

Source of Support: Nil; Conflict of Interest: None

Submitted: 30-12-2019; Accepted: 24-01-2020; Published online: 25-02-2020 